\title{
CERUMINOUS ADENOMA OF EXTERNAL AUDITORY CANAL IN A YOUNG ADULT: A RARE CASE REPORT
}

\author{
Anuradha G. Patil ${ }^{1}$, Ashok Patil2 ${ }^{2}$, Shabnam Karangadan ${ }^{3}$
}

\section{HOW TO CITE THIS ARTICLE:}

Anuradha G. Patil, Ashok Patil, Shabnam Karangadan. "Ceruminous Adenoma of External Auditory Canal in a Young Adult: A Rare Case Report". Journal of Evolution of Medical and Dental Sciences 2014; Vol. 3, Issue 32, August 04; Page: 8791-8794, DOI: 10.14260/jemds/2014/3124

ABSTRACT: Ceruminous adenoma is a benign glandular neoplasm of ceruminous glands that arises solely from the external auditory canal. It is a rare neoplasm accounting for $<1 \%$ of all external ear tumors, usually affecting middle-aged patients, without gender predilection. We report a unique case of ceruminous adenoma of external auditory canal in an 18years male which is a rarely encountered age for this tumor. They demonstrate a dual cell population of basal myoepithelial-type cells and luminal ceruminous cells. Complete surgical excision results in an excellent long-term clinical outcome. The distinctive architecture and histology of these neoplasms allow for their separation from other neoplasms in this area, which contributes to appropriate clinical management of these tumors.

KEYWORDS: Ceruminous adenoma, mixed tumor, external auditory canal.

KEYMESSAGES: Ceruminous adenomas are rare benign glandular tumor of external auditory canal of ceruminous gland origin. Its distinctive histology separates them from other neoplasms in this area, which contributes to appropriate clinical management of these tumors. The uniqueness of this case lies in the presentation in a young adult.

INTRODUCTION: Ceruminous adenoma is a benign glandular neoplasm of ceruminous glands that arises solely from the external auditory canal. It is a rare neoplasm accounting for $<1 \%$ of all external ear tumors, usually affecting middle-aged patients, without gender predilection. ${ }^{1}$ About 150 cases of ceruminous adenoma have been reported in the literature. ${ }^{2}$ It is rarely encountered in younger age group. Hence we report a unique case of ceruminous adenoma of external auditory canal in a young adult.

CASE HISTORY: 18years old male presented with pedunculated firm painless swelling in left external auditory canal with blocking sensation and intermittent ear pain.

Grossly, skin covered globular mass with a diameter of $1 \mathrm{~cm}$. Cut section was homogeneous solid and grey white. On microscopy, sections reveal epidermis and dermis. Dermis is showing unencapsulated, well circumscribed tumor composed of dilated glands, solid sheets and nests of tumor cells with areas of fibrosis, myxoid pseudocartilaginous stroma and occasional papillary structures. Glands are lined by double layer of basal myoepithelial and luminal cuboidal cells. These cells are having abundant eosinophilic granular cytoplasm, mildly pleomorphic nuclei and prominent nucleoli in few of them.

DISCUSSION: Ceruminous glands are modified apocrine sweat glands limited to outer $1 / 3$ of external auditory canal. The ceruminal glands are deep within the dermis and are comprised of columnar cells containing intensely eosinophilic cytoplasm, frequently displaying secretory snouts surrounded by a 
layer of myoepithelial cells. The luminal secretory cells contain cytoplasmic golden yellow brown water insoluble lipoprotein pigment granules which are PAS positive, sudan black positive and stains with Ziehl- Neelsen acid fast method. The presence of these granules confirms the ceruminous origin of neoplasm. ${ }^{3}$

Ceruminous adenoma is classified as a well differentiated, benign neoplasm, localized, occasionally cystic and showing papillary proliferation of glands histologically similar to normal ceruminous glands. ${ }^{3}$ It occurs with equal frequency in men and women with a mean age of 49 years. ${ }^{4}$

The present case is of an 18year old male which is relatively a younger age compared to the mean age. The youngest reported case was in a 12year old. ${ }^{3}$

Patients usually present with a mass that is most often on the posterior wall of the outer onethird of the external auditory canal and may be associated pain, hearing loss, tinnitus, or even paralysis of the nerves. ${ }^{1}$

Grossly, most of these tumors are small (mean, $1.2 \mathrm{~cm}$ ), largely a function of the anatomic confines of the region ${ }^{1}$. They are non-ulcerated, polypoid superficial mass of a red to tan appearance, with cut surface showing occasional small cysts in outer half of external auditory canal and having mean size of $1.2 \mathrm{~cm}^{5}$

On microscopy ceruminous adenomas are composed of well differentiated tubular, ductal, or papillary structures reminiscent of ceruminous glands. Two distinct cell layers of inner luminal secretory cells that contain ceroid pigment and display apical secretion by decapitation and outer or basal myoepithelial cells are easily identified. They usually lack invasion, perineural growth, profound nuclear pleomorphism, mitotic activity, tumor necrosis, and haemorrhage. ${ }^{3}$

Other tumors of ceruminous gland origin, includes ceruminous pleomorphic adenoma, Ceruminous syringocystadenoma papilliferum and ceruminous adenocarcinoma and tumors seen around this anatomical site comprise of neuroendocrine adenoma of the middle ear, parotid pleomorphic adenoma, meningioma and paraganglioma. All these can be easily distinguished from ceruminous adenoma by histology. ${ }^{3}$

Ancillary tests like immune-histochemistry and electron microscopy can be used, though not diagnostic but can be used to highlight the biphasic nature of the tumor cells. The luminal cells will be positive for CK7, EMA and pankeratin; the latter two are also positive in the basal cells. Additionally, the basal cells will stain with CK5/6, p63, and S-100 protein. ${ }^{1}$

On electron microscopy, ceruminous gland adenoma showed apocrine caps, microvilli, cell junctions, secretory granules, vacuoles, lipid droplets and siderosomes, the characteristic ultrastructural features of apocrine glands. ${ }^{4}$

The treatment of choice for ceruminous adenomas is complete surgical excision. Complete excision will be curative, with incomplete excision associated with an increased risk of recurrence. ${ }^{5}$

CONCLUSION: Ceruminous adenomas are rare benign glandular tumor of external auditory canal of ceruminous gland origin. The unique architecture and histology of these neoplasms allow for their separation from other neoplasms in this area, which contributes to appropriate clinical management of these tumors. Limited documentation and rarity of these tumors especially in this age group prompted us to present this case. 


\section{REFERENCES:}

1. Thompson LDR. Ear ceruminous adenoma. Ear Nose Throat J. 2011; 90 (7): 304-5.

2. Magliulo G, Bertin S. Adenoma of the ceruminous gland. Otolaryngology-Head and Neck Surgery. 2010; 143: 459-460.

3. Thompson LDR, Nelson BL, Barnes EL. Ceruminous adenomas- a clinicopathological study of 41 cases with a review of the literature.Am J Surg Pathol. 2004; 28 (3): 308-318.

4. Thompson LDR, Michaels L. Ceruminous gland neoplasms of external auditory canal and cylindroma. In: Barnes L, Eveson JW, Reichart P, Sidransky D. World Health Organisation Classification of Tumours. Pathology and Genetics of Head and Neck Tumours. Lyon: IARC Press. 2005: 331-333.

5. Thompson LDR. Benign neoplasms of the ear and temporal bone. In: Thompson LDR, Goldblum JR. Head and Neck Pathology- A volume in the series Foundations in Diagnostic Pathology. 2nd edition. Philadelphia: Saunders; 2012: 422-447.

Fig. 1A: Unencapsulated well circumscribed tumor within the dermis composed of ceruminous glands of varying sizes in fibromyxoid stroma with overlying keratinized squamous epithelium (H\&E 100x).

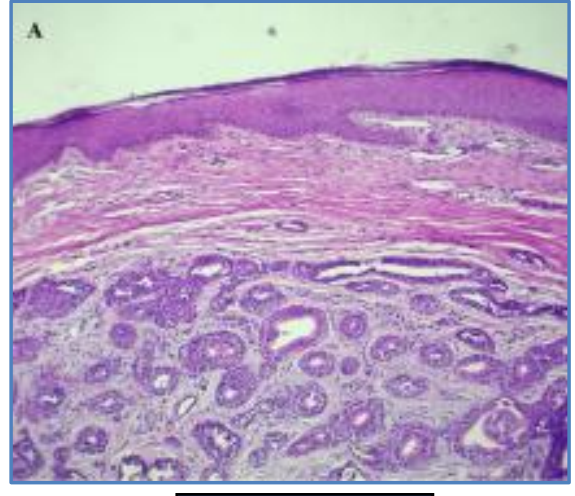

\section{Figure 1A}

Fig. 1B: Higher magnification showing glands lined by basal myoepithelial and luminal cuboidal cells, that have abundant eosinophilic granular cytoplasm and mildly pleomorphic nucleus (H\&E 400x)

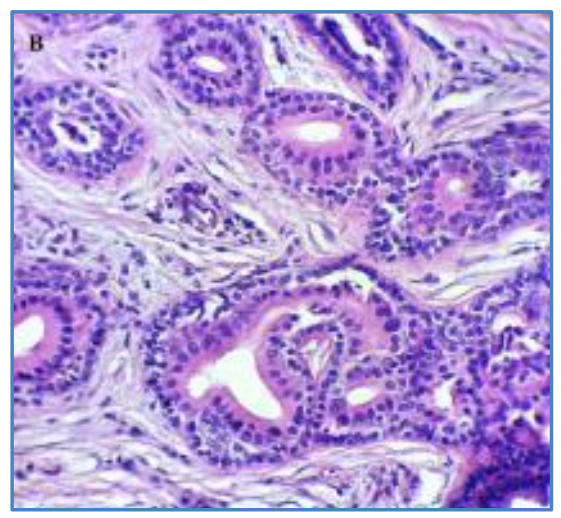

Figure 1B 


\section{CASE REPORT}

\section{AUTHORS:}

1. Anuradha G. Patil

2. Ashok Patil

3. Shabnam Karangadan

\section{PARTICULARS OF CONTRIBUTORS}

1. Professor, Department of Pathology, M.R. Medical College, Gulbarga, Karnataka.

2. Consultant, Dr. T. A. Patil's ENT Clinic, Gulbarga, Karnataka.

3. Resident, Department of Pathology, M.R. Medical College, Gulbarga, Karnataka.

\section{NAME ADDRESS EMAIL ID OF THE} CORRESPONDING AUTHOR:

Dr. Anuradha G. Patil,

C/o. T. A. Patil,

Geetha, Behind District Court,

Gulbarga-585102,

Karnataka.

Email: patilanuradha99@yahoo.com shabnamk126@gmail.com

Date of Submission: 17/07/2014.

Date of Peer Review: 18/07/2014.

Date of Acceptance: 28/07/2014.

Date of Publishing: 02/08/2014. 